\title{
A Detection Method of Ectocervical Cell Nuclei for Pap test Images, Based on Adaptive Thresholds and Local Derivatives
}

\author{
Julio Oscanoa ${ }^{1}$, Marcelo Mena ${ }^{2}$ and Guillermo Kemper $^{3}$ \\ University of Applied Sciences (UPC), Lima-Peru \\ 1julioscanoa@gmail.com, 2 maecc008@hotmail.com, ${ }^{3}$ guillermo.kemper@gmail.com
}

\begin{abstract}
Cervical cancer is one of the main causes of death by disease worldwide. In Peru, it holds the first place in frequency and represents $8 \%$ of deaths caused by sickness. To detect the disease in the early stages, one of the most used screening tests is the cervix Papanicolaou test. Currently, digital images are increasingly being used to improve Pap test efficiency. This work develops an algorithm based on adaptive thresholds, which will be used in Pap smear assisted quality control software. The first stage of the method is a pre-processing step, in which noise and background removal is done. Next, a block is segmented for each one of the points selected as not background, and a local threshold per block is calculated to search for cell nuclei. If a nucleus is detected, an artifact rejection follows, where only cell nuclei and inflammatory cells are left for the doctors to interpret. The method was validated with a set of 55 images containing 2317 cells. The algorithm successfully recognized $92.3 \%$ of the total nuclei in all images collected.
\end{abstract}

Keywords: Cervical cancer, medical image processing, nuclei detection

\section{Introduction}

Cervical cancer is one of the main causes of morbi-mortality in women around the world, and it constitutes the second most frequent malignant tumor both in incidence and mortality in women from all ages. In Latin America, it is estimated that 63,608 women are diagnosed with cervical cancer annually, while 29,222 deceases are recorded as consequence of this disease [1]. In Peru, cervical cancer holds the first place in frequency (14.9\%), accounting for a total of 109,914 notified cases between 2006 and 2011. Out of these, $5.6 \%$ were diagnosed through an early detection or screening program. Furthermore, the number of healthy life years lost to cancer was 418,960 in 2008, which represented $8 \%$ of the national disease load [2]. Currently, 75\% of the diagnostics are done when the disease is in an advanced stage [3]. Consequently, the application of a screening exam in the public health strategy is vital. The two most used tests are the conventional exfoliative cervicovaginal cytology (cervix Papanicolaou test) and Human Papiloma Virus (HPV) detection tests. Papanicolaou cytology has a sensitivity (probability to correctly identify a sick woman) of $44 \%$ to $86 \%$ and a specificity (probability to correctly identify a healthy woman) of $98 \%$ [4].

Among the limitations of the Pap cervix, which contribute to its low sensitivity, are the difficulty to obtain an adequate sample, the bias between observers, and the misinterpretations. Even with adequate samples, a percentage of discrepancy between $9.8 \%$ and $15 \%$ has been observed in the cytological classification of the lesions [5]. To overcome these problems, there is nowadays an increasing use of digital image in cytopathology. The accessibility that digital cytology provides can improve the quality and efficiency of 
cytopathology services. Some of the fields being exploited include tele-education, telecytology, quality assurance and automated/assisted screening of Pap test slides [6]. However, digital image brings with itself problems caused by the acquisition systems, such as non-uniform illumination or low contrast. Likewise, there are some problems caused by the stratified nature of the tissue, like folded and overlapped cells, and the common presence of mucus, blood cells and other artifacts that disturb the sample [7].

As for the illumination problem, there is a grey reescalation based on the gray weighted barycenter in [8], and a HSI color model approach in [9]. In [10], part of the preprocessing is edge sharpening and contrast enhancement, within the three RGB layers, using h-minima transform. On the other hand, [11] uses marker-based watershed segmentation to prevent oversegmentation and inaccurate boundary segmentation. Additionally, in [12] an overlapping cell segmentation algorithm is developed using a spatially adaptive active physical model. Finally, the area, elliptical shape, and texture/granularity are considered for artifact rejection in [13]. Regarding the detection algorithms previously developed, there have been several approaches, such as global and adaptive thresholds [8, 14], the watershed transform [11-13] and even a fuzzy logic based algorithm [9]. However, the thresholding algorithms lack robustness when faced to problems such as noise, uneven illumination and variations in staining intensity. Additionally, the watershed transform algorithms are prone to oversegmentation and inaccurate boundary segmentation $[13,15]$. Finally, in most algorithms proposed there is a need for a larger and more diverse set of validation images, as the average number of images used in each project does not exceed twenty.

The approach of this paper is to develop a simple and computationally inexpensive algorithm that can be used in assisted screening software for cytopathologist. For this purpose, the aforementioned problems related to thresholding algorithms shall be overcome. Additionally, an extensive set of images will be prepared to correctly evaluate the algorithm performance.

\section{Proposed Method}

The algorithm proposed is designed to detect and segment free-lying ectocervical cell nuclei, which are the most abundant on Pap smears. The approach chosen was a threshold-based algorithm. Thus, problems related to noise, uneven illumination and variations in staining intensity shall be overcome. In this manner, a point-to-point analysis, detailed in this paper, was developed. The general diagram is shown in Figure 1. After image acquisition, the method is divided in three main stages: preprocessing, block analysis, and artifact rejection. Then, as shown in the diagram, a false color representation is elaborated with the results.

The first step is image acquisition. The digital smear images used in this work were captured by a camera adapted to an optical microscope with a 40x magnification; while the storing was made with $4096 \times 3084$ pixels in format ORF. Then, the method is divided in three main stages: Preprocessing, Block analysis, and Artifact rejection. 


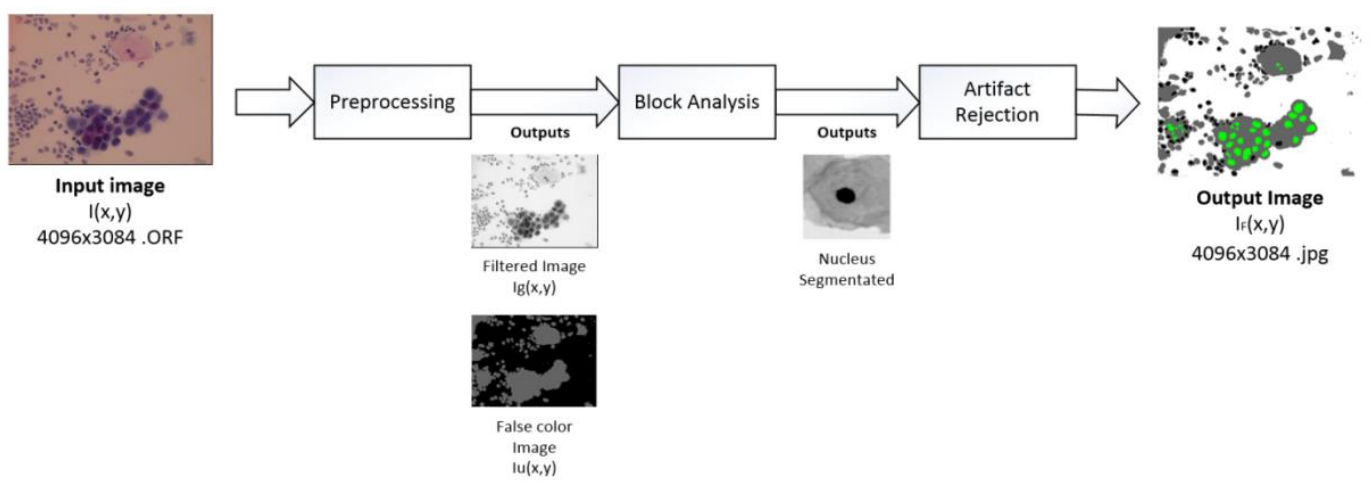

Figure 1. Block Diagram of Proposed Method

The Preprocessing stage deals with the problem of noise and makes a pre-selection of areas of interests, removing the background in order to improve the processing time. A for loop is made with all the pixels selected as area of interest and the Block Analysis is executed for each one. This approach was taken to overcome the aforementioned issues of uneven illumination and variations in staining intensity. If a potentially nucleus is identified in the block, an Artifact Rejection step follows. Finally, as this project was intended for quality assurance assisted software, additionally to statistics, a false color representation was elaborated for each image in order to present results to the doctors.

\subsection{Preprocessing}

Acquired color image I (Figure 2) with RGB primary components $I_{R}(x, y), I_{G}(x, y)$ and $I_{B}(x, y)$ ) is converted to grayscale as follows:

$$
I_{d}(x, y)=a_{1} I_{R}(x, y)+a_{2} I_{G}(x, y)+a_{3} I_{B}(x, y)
$$

where $a_{1}=0.299, a_{2}=0.587$ and $a_{3}=0.114$

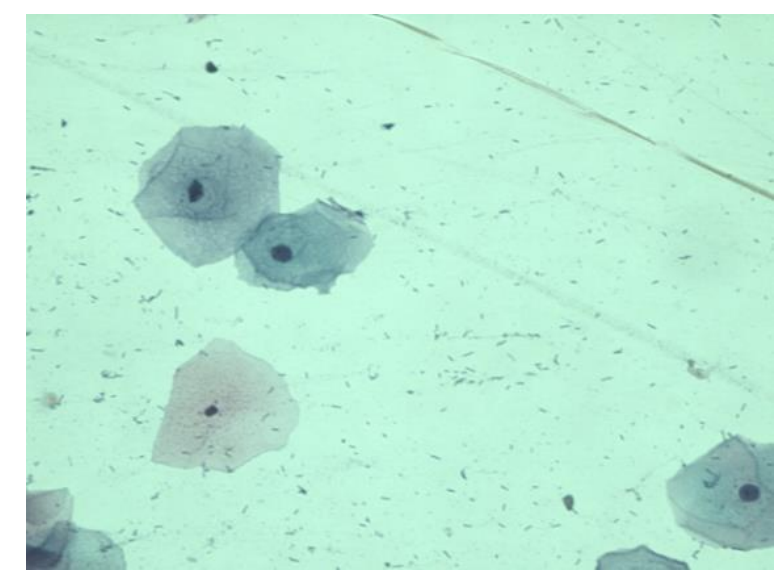

Figure 2. Original Image

A median filter is applied to remove the impulse noise inherent to all digital images. These filters have been widely used in the removal of salt-and-pepper type impulse 
noise, due to its simplicity yet high effectiveness [16]. The resulting filtered image is defined as $\mathrm{I}_{\mathrm{g}}(\mathrm{x}, \mathrm{y})$.

The histogram of $\mathrm{I}_{\mathrm{g}}(\mathrm{x}, \mathrm{y})$ is defined as $\mathrm{h}_{\mathrm{Ig}}(\mathrm{r})$, where " $\mathrm{r}$ " is the shade of gray defined in the range [0,255] (Figure 3a). While the derivative of $\mathrm{h}_{\mathrm{Ig}}(\mathrm{r})$ in absolute value (Figure 3b) is obtained as follows:

$$
d h_{I_{g}}(r)=\left|h_{I_{g}}(r)-h_{I_{g}}(r-1)\right|
$$

From $h_{I g}(r)$ and $d h_{I g}(r)$, a global threshold is determined to segment the regions with presence of cell nuclei. The procedure is described below:

1. $\mathrm{dh}_{\mathrm{Ig}}^{\prime}(\mathrm{r})$ is defined as follows:

$$
\operatorname{dh}_{\mathrm{Ig}_{\mathrm{g}}}^{\prime}(\mathrm{r})\left\{\begin{array}{cr}
0, & 0 \leq \mathrm{r} \leq 122 \\
\mathrm{dh}_{\mathrm{I}_{\mathrm{g}}}(\mathrm{r}), & \text { otherwise }
\end{array}\right.
$$

2. The value of $r_{0}$ meeting the next condition is searched:

$$
\mathrm{dh}_{\mathrm{I}_{\mathrm{g}}}^{\prime}\left(\mathrm{r}_{0}\right)>\mathrm{dh}_{\mathrm{I}_{\mathrm{g}}}^{\prime}(\mathrm{r}) \text {, for all } \mathrm{r} \neq \mathrm{r}_{0}
$$

3. Let $r_{A}=r_{0}$ and a temporal flag $b_{u}=0$

4. " $\mathrm{b}_{\mathrm{u}}$ " is updated with the following expression:

$$
\mathrm{b}_{\mathrm{u}}=\left\{\begin{array}{cc}
1, & \mathrm{dh}_{\mathrm{I}_{\mathrm{g}}}^{\prime}\left(\mathrm{r}_{\mathrm{A}}\right)<50 \wedge d \mathrm{~h}_{\mathrm{I}_{\mathrm{g}}}^{\prime}\left(\mathrm{r}_{\mathrm{A}}-1\right)<50 \wedge \mathrm{dh}_{\mathrm{I}_{\mathrm{g}}}^{\prime}\left(\mathrm{r}_{\mathrm{A}}-2\right)<50 \\
0, & \text { otherwise }
\end{array}\right.
$$

5. If $b_{u}=1$, then the global threshold is set $u_{g}=r_{A}$; otherwise, $r_{A}=r_{A}-1$ and the procedure is repeated from step 4.

Once $u_{g}$ is found, a thresholded image is obtained with the following expression:

$$
I_{u}(x, y)=\left\{\begin{array}{cc}
0, & I_{g}(x, y) \geq u_{g} \\
100, & I_{g}(x, y)<u_{g}
\end{array}\right.
$$

The result of this stage is shown in Figure 4, where the pixels belonging to the background are black and will not be analyzed in the next parts. The rest, i.e. regions with potential cell nuclei, is gray.

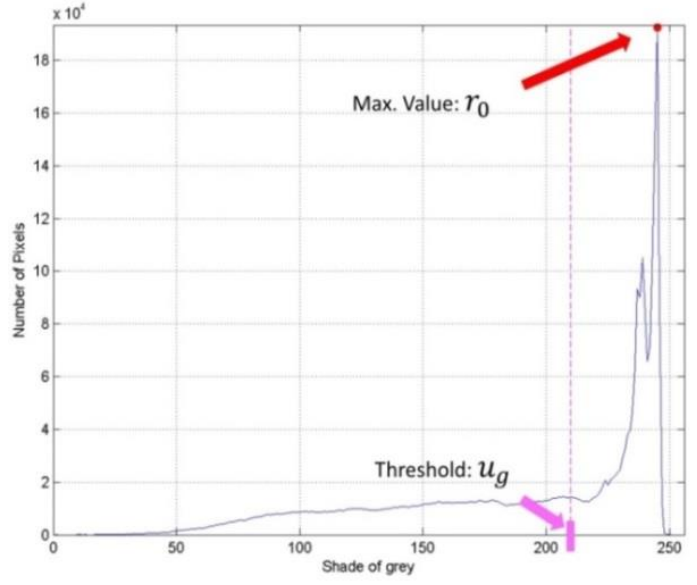

(a) Grayscale Histogram

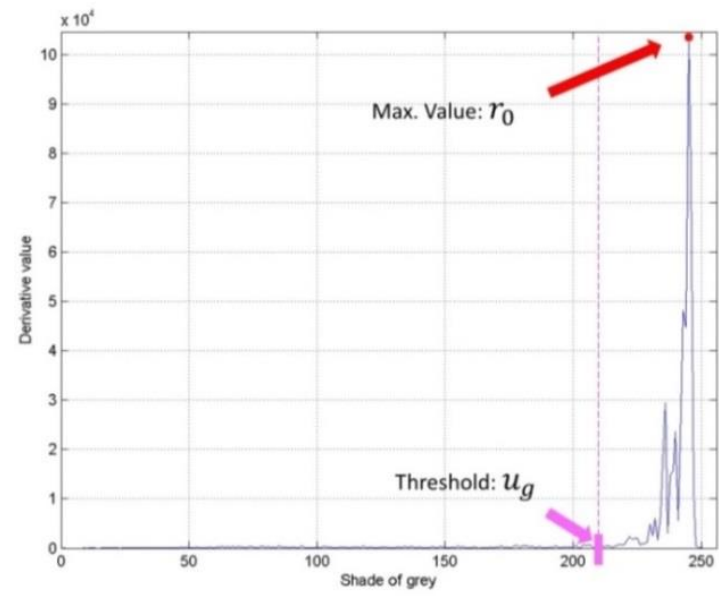

(b) Derivative of the Histogram

Figure 3. Global Threshold Calculation 


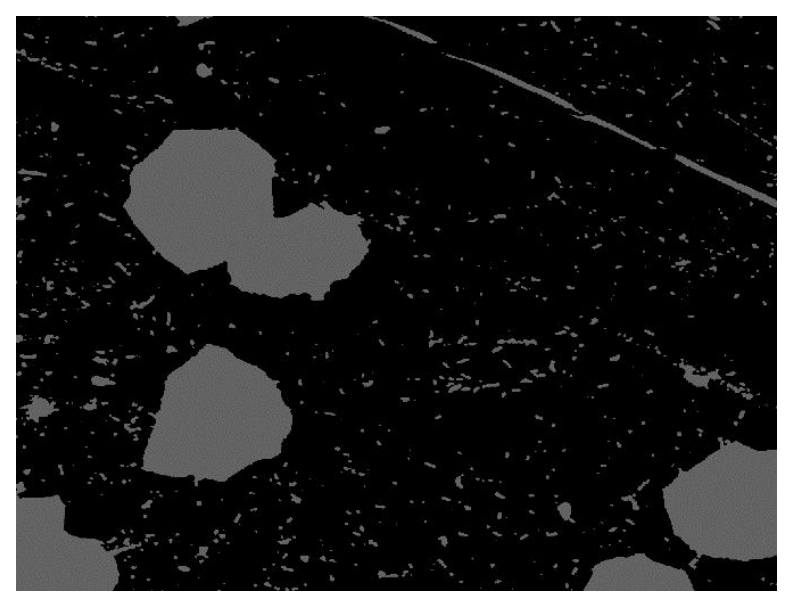

\section{Figure 4. Result from the Global Threshold Clculation $I_{u}(x, y)$}

\subsection{Block Analysis}

With the thresholded image and the grayscale filtered image $\left(I_{g}\right)$, a Block analysis follows. Image $I_{u}(x, y)$ is scanned from left to right and top to bottom to find the coordinates where $I_{u}(x, y)=100$. The process is followed as described below:

1. $\mathrm{I}_{\mathrm{u}}\left(\mathrm{x}_{0}, \mathrm{y}_{0}\right)$ shall be defined as the first detected pixel with value 100 . Then an image block is segmented, which is expressed as:

$$
I_{b}(x, y)=I_{g}\left(x+x_{0}-\frac{M 1}{2}, y+y_{0}-\frac{N 1}{2}\right)
$$

where $x=0,1,2, \ldots, M 1$ and $y=0,1,2, \ldots, N 1$. In this case, we consider $M 1=300$ and $\mathrm{N} 1=300$.

2. Row $\mathrm{M} 1 / 2$ and column $\mathrm{N} 1 / 2$ of $\mathrm{I}_{\mathrm{b}}(\mathrm{x}, \mathrm{y})$ are extracted:

$$
\begin{aligned}
& V_{h}(y)=I_{b}\left(\frac{M 1}{2}, y\right), y=0,1,2, \ldots, N 1 \\
& V_{v}(x)=I_{b}\left(x, \frac{N 1}{2}\right), x=0,1,2, \ldots, M 1
\end{aligned}
$$

3. The derivative of $V_{h}(x)$ is obtained:

$$
\mathrm{V}_{\mathrm{h}}^{\prime}(\mathrm{y})=\mathrm{V}_{\mathrm{h}}(\mathrm{y})-\mathrm{V}_{\mathrm{h}}(\mathrm{x}-1)
$$

4. $\mathrm{y}_{\mathrm{A}}=\mathrm{N} 1 / 2$ and a temporal flag $\mathrm{b}_{\mathrm{h}}=0$ are defined

5. " $\mathrm{b}_{\mathrm{h}}$ " is updated with the following expression:

$$
\mathrm{b}_{\mathrm{h}}=\left\{\begin{array}{cc}
1, & \mathrm{~V}_{\mathrm{h}}^{\prime}\left(\mathrm{y}_{\mathrm{A}}\right)<-3 \wedge \mathrm{V}_{\mathrm{h}}^{\prime}\left(\mathrm{y}_{\mathrm{A}}-1\right)<\mathrm{V}_{\mathrm{h}}^{\prime}\left(\mathrm{y}_{\mathrm{A}}\right) \wedge \\
& \mathrm{V}_{\mathrm{h}}^{\prime}\left(\mathrm{y}_{\mathrm{A}}-2\right)<\mathrm{V}_{\mathrm{h}}^{\prime}\left(\mathrm{y}_{\mathrm{A}}\right) \wedge \mathrm{V}_{\mathrm{h}}^{\prime}\left(\mathrm{y}_{\mathrm{A}}+2\right)<\mathrm{V}_{\mathrm{h}}^{\prime}\left(\mathrm{y}_{\mathrm{A}}\right) \\
0, & \text { otherwise }
\end{array}\right.
$$

6. If $b_{h}=1$, then $y_{1}=y_{A}$. Otherwise, $y_{A}=y_{A}-1$ and the procedure is repeated from step 6. In case $b_{h}=1$ is never reached, the process ends and the next 100 value pixel is analyzed from step 2 .

7. $\mathrm{b}_{\mathrm{h}}=0$ again and $\mathrm{y}_{\mathrm{A}}=\mathrm{N} 1 / 2$.

8. Then, " $\mathrm{b}_{\mathrm{h}}$ " is updated with the following expression:

$$
b_{h}=\left\{\begin{array}{cc}
1, & V_{h}^{\prime}\left(y_{A}\right)>3 \wedge V_{h}^{\prime}\left(y_{A}-1\right)>V_{h}^{\prime}\left(y_{A}\right) \wedge V_{h}^{\prime}\left(y_{A}+1\right)>V_{h}^{\prime}\left(y_{A}\right) \wedge \\
0, & V_{h}^{\prime}\left(y_{A}-2\right)>V_{h}^{\prime}\left(y_{A}\right) \wedge V_{h}^{\prime}\left(y_{A}+2\right)>V_{h}^{\prime}\left(y_{A}\right) \\
\text { otherwise }
\end{array}\right.
$$


9. If $b_{h}=1$, then $y_{2}=y_{A}$. Otherwise, $y_{A}=y_{A}+1$ and the procedure is repeated from step 9. In case $b_{h}=1$ is never reached, the process ends and the next 100 value pixel is analyzed from step 2 .

10. In the same manner, the process is repeated analogously for $V_{v}(x)$ from step 4 to 10 .

11. If coordinates $\mathrm{x}_{1}, \mathrm{x}_{2}, \mathrm{y}_{1}$ and $\mathrm{y}_{2}$ are found, vectors $\mathrm{V}_{\mathrm{v}}(\mathrm{x})$ and $\mathrm{V}_{\mathrm{h}}(\mathrm{y})$ are segmented:

$$
\begin{aligned}
& V_{v s}(x)=V_{v}\left(x+x_{1}\right), x=0,1, \ldots, x_{2}-x_{1} \\
& V_{h s}(y)=V_{h}\left(y+y_{1}\right), y=0,1, \ldots, y_{2}-y_{1}
\end{aligned}
$$

In Figure 5a, there is an extracted block example, where the red circle indicates the position of the point being analyzed. The white line is the middle row being extracted for the derivative calculation and the black line represents the part of the row that belongs to a nucleus. In Figure 5b, the derivative is plotted, where the red lines indicate where cell nucleus limits were found.

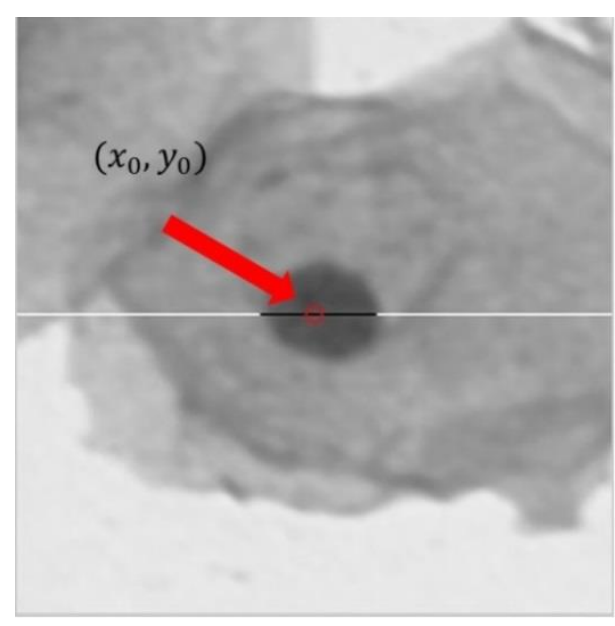

(a) Vector Analysis in the Block.

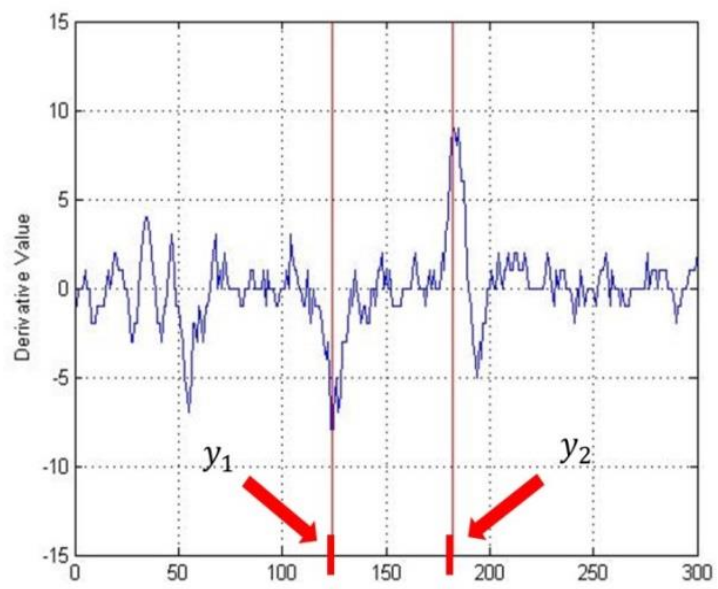

(b) Derivative of Row Vector.

Figure 5. Block Analysis

12. The maximum $P_{\max }$ value for both vectors $V_{v s} y V_{h s}$ is obtained:

$$
\mathrm{P}_{\text {max }}=\max \left(\mathrm{V}_{\mathrm{vs}}\left(\mathrm{x}_{\mathrm{B}}\right), \mathrm{V}_{\mathrm{hs}}\left(\mathrm{y}_{\mathrm{B}}\right)\right)
$$

where $V_{v s}\left(x_{B}\right)$ and $V_{h s}\left(y_{B}\right)$ meet the following conditions:

$$
\begin{aligned}
& V_{v s}\left(x_{B}\right) \geq V_{v s}(x), \text { for } x=0,1, \ldots, x_{2}-x_{1} \\
& V_{h s}\left(y_{B}\right) \geq V_{h s}(y), \text { for } y=0,1, \ldots, y_{2}-y_{1}
\end{aligned}
$$

Function $\max (\mathrm{a}, b)$ returns the largest value (a or $\mathrm{b}$ )

13. Block $\mathrm{I}_{\mathrm{b}}(\mathrm{x}, \mathrm{y})$ is thresholded:

$$
I_{s}(x, y)=\left\{\begin{array}{cc}
255, & I_{b}(x, y)<P_{\max } \\
0, & \text { otherwise }
\end{array}\right.
$$

14. A labeling algorithm [17] is applied to the binary image $I_{S}\left(x, y\right.$, and $I_{L}(x, y)$ is obtained (See Figure 6a).

15. The object (label) almost centralized in the coordinates $(x=M 1 / 2, y=N 1 / 2)$ is 
extracted.

16. $I_{0}(x, y)$ shall be defined as the binary image only containing the object segmented, which has dimensions M1 and N1 (See Figure 6b).

\subsection{Artifact Rejection I}

In order to obtain a good segmentation of nuclei and to discern between them and artifacts, a parameter extraction and evaluation is performed with $\mathrm{I}_{0}(\mathrm{x}, \mathrm{y})$.

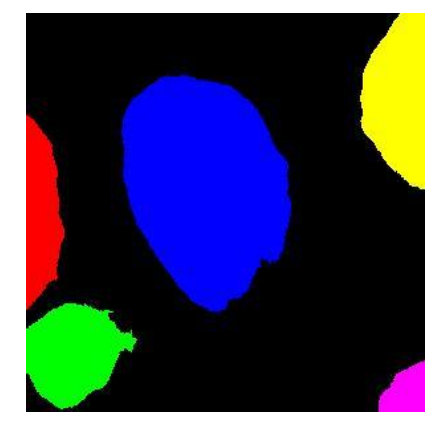

(a) Image after Labeling.

Each Color Represents a Different Object (label)

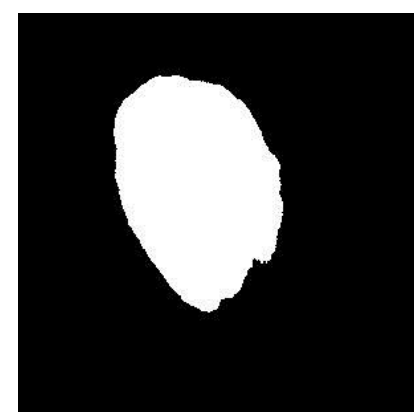

(b) Single Cell Extraction. Cell almost Centralized in $(x=M 1 / 2, y=N 1 / 2)$

Figure 6. Labeling Algorithm

17. Area $A_{c}$ shall be defined as the number of pixels meeting the condition $I_{0}(x, y)=$ 255. In this case, $A_{c}$ can be expressed as:

$$
A_{c}=\frac{1}{255} \sum_{x=0}^{M 1-1} \sum_{y=0}^{N 1-1} I_{0}(x, y)
$$

18. Perimeter $\mathrm{P}_{c}$ of the extracted cell in $\mathrm{I}_{0}(\mathrm{x}, \mathrm{y})$ is obtained through the following expression:

$$
P_{c}=\sum_{x=0}^{M 1-1} \sum_{y=0}^{N 1-1} I_{p}(x, y)
$$

where:

$\mathrm{I}_{\mathrm{p}}(\mathrm{x}, \mathrm{y})=\left\{\begin{array}{c}1, \quad \mathrm{I}_{0}(\mathrm{x}, \mathrm{y})=255 \wedge\left\{\mathrm{I}_{0}(\mathrm{x}-1, \mathrm{y})=0 \vee \mathrm{I}_{0}(\mathrm{x}+1, \mathrm{y})=0\right. \\ \vee \mathrm{I}_{0}(\mathrm{x}-1, \mathrm{y}-1)=0 \vee \mathrm{I}_{0}(\mathrm{x}, \mathrm{y}-1)=0 \vee \mathrm{I}_{0}(\mathrm{x}+1, \mathrm{y}-1)=0 \\ \mathrm{~V} \mathrm{I}_{0}(\mathrm{x}-1, \mathrm{y}+1)=0 \vee \mathrm{I}_{0}(\mathrm{x}, \mathrm{y}+1)=0 \vee \mathrm{I}_{0}(\mathrm{x}+1, \mathrm{y}+1)=0 \\ 0, \quad \text { otherwise }\end{array}\right.$

19. The Quotient (used to determine whether the object has a regular elliptical shape or not) shall be defined as:

$$
\mathrm{Q}=\mathrm{P}_{\mathrm{C}} / \mathrm{A}_{\mathrm{C}}
$$

20. Once the parameters are calculated, a temporal flag is defined $b_{0}=0$

21. $" b_{0}$ " is updated with the following expression:

$$
\mathrm{b}_{0}=\left\{\begin{array}{cc}
1, & \mathrm{~A}_{\mathrm{C}}<\mathrm{u}_{\mathrm{A}} \wedge \mathrm{Q}<\mathrm{u}_{\mathrm{Q}} \\
0, & \text { otherwise }
\end{array}\right.
$$

Thresholds " $\mathrm{u}_{\mathrm{Q}}$ " and " $\mathrm{u}_{\mathrm{A}}$ " were obtained by experience. " $\mathrm{u}_{\mathrm{Q}}$ " had a value of 19 ; whereas $u_{A}$ is image size dependent, the minimum area for the pictures used in this 
work was 1000 pixels, but the developed software has an option to change this value depending on the image zoom.

22. If $\mathrm{b}_{0}=1$, the pixels belonging to the cell nucleus are set to 255 in $\mathrm{I}_{\mathrm{u}}(\mathrm{x}, \mathrm{y})$, as shown in Figure $7 \mathrm{~b}$. Otherwise, the process ends and the next 100-value pixel is analyzed from step 2.

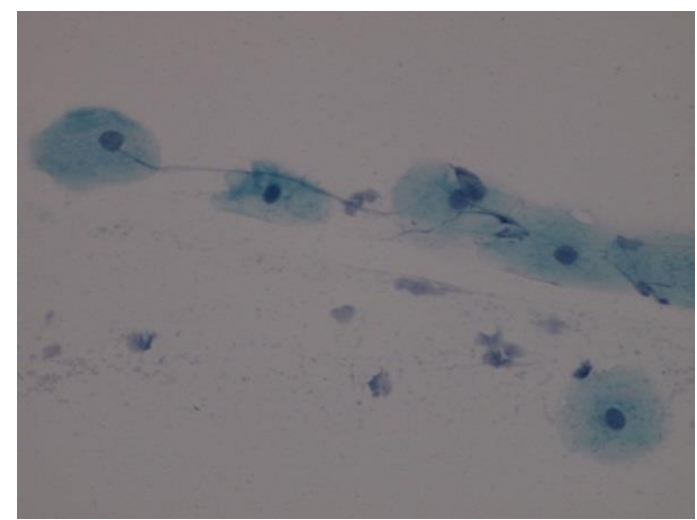

(a) Original Image

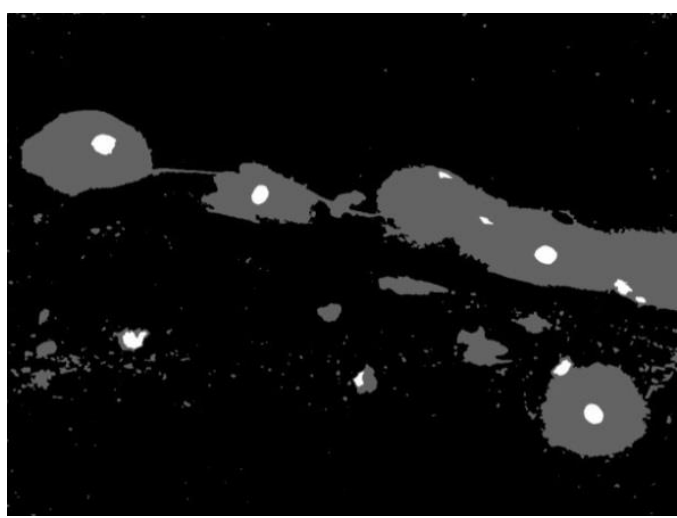

(b) False Color Image $I_{u}(x, y)$

Figure 7. Result from the Cell Nuclei Identification

After all $\mathrm{I}_{\mathrm{u}}(\mathrm{x}, \mathrm{y})=100$ coordinates are analyzed, the same procedure from step 1 to 25 at the block analysis is repeated, with the exception that in step 14 the threshold used is:

$$
\mathrm{P}_{0}=\frac{\sum_{\mathrm{y}=0}^{\mathrm{y}_{2}-\mathrm{y}_{1}} \mathrm{~V}_{\mathrm{hs}}(\mathrm{y})+\sum_{\mathrm{x}=0}^{\mathrm{x}_{2}-\mathrm{x}_{1}} \mathrm{~V}_{\mathrm{vs}}(\mathrm{x})}{\left(\mathrm{y}_{2}-\mathrm{y}_{1}\right)+\left(\mathrm{x}_{2}-\mathrm{x}_{1}\right)+2}
$$

This step was included in order to detect some cell nuclei too close to each other or not well defined.

\subsection{Artifact Rejection II (Inflammatory cells)}

Some of the images presented inflammatory cells, which were similar in size and shape to the smallest cell nuclei. Thus, to be considered a cell nucleus, each identified object needed to be surrounded by cytoplasm or not-background, i.e., surrounded by pixels $\mathrm{I}_{\mathrm{u}}(\mathrm{x}, \mathrm{y})=100$.

The labeling algorithm is applied to $I_{u}(x, y)$, where $I_{u}(x, y)=255$. Then, for each identified object, the following procedure is done:

1. The first object is segmented from $I_{u}(x, y)$, and $I_{1}(x, y)$ is obtained (see Figure 8a).

2. The minimum vertical coordinate, where $\mathrm{I}_{1}(\mathrm{x}, \mathrm{y})=255$, is defined as $\mathrm{x}_{\min }$. In the same manner, the minimum horizontal coordinate $y_{\min }$ is determined.

3. The maximum vertical coordinate, where $\mathrm{I}_{1}(\mathrm{x}, \mathrm{y})=255$, is defined as $\mathrm{x}_{\max }$. Under the same condition, the maximum horizontal coordinate $\mathrm{y}_{\max }$ is determined.

4. From $I_{u}(x, y)$, an image block is segmented (see Figure $8 b$ ), which is defined as:

$$
\mathrm{I}_{2}(\mathrm{x}, \mathrm{y})=\mathrm{I}_{\mathrm{u}}\left(\mathrm{x}-\mathrm{x}_{\min }, \mathrm{y}-\mathrm{y}_{\min }\right)
$$

where: $\mathrm{x}=0,1,2, \ldots, \mathrm{x}_{\max }-\mathrm{x}_{\min }$ and $\mathrm{y}=0,1,2, \ldots, \mathrm{y}_{\max }-\mathrm{y}_{\min }$ 


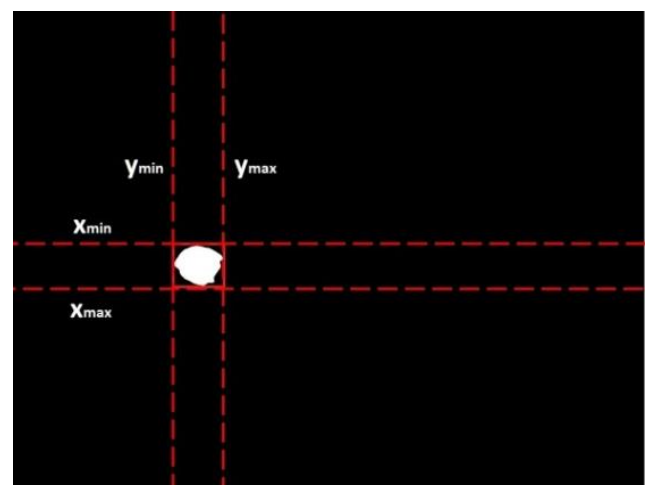

(a) Segmented Cell Nucleus $I_{1}(x, y)$

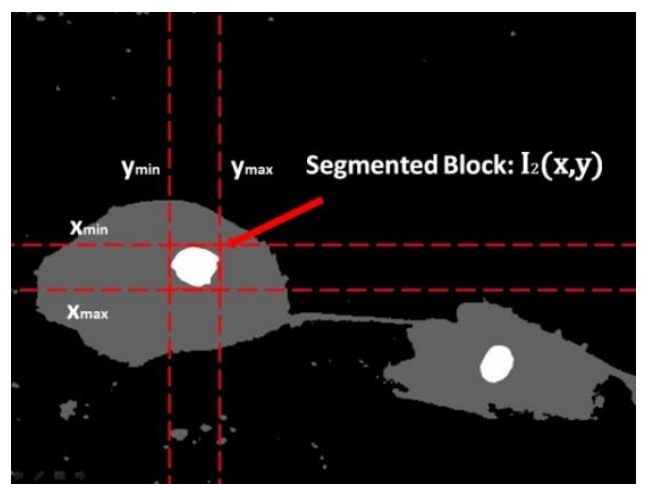

(b) Segmented Block $I_{2}(x, y)$ from $I_{u}(x, y)$

\section{Figure 8. Inflammatory Cell Rejection}

5. The segmented object is set as a true nucleus if:

For all points in:

$$
\mathrm{I}_{2}(\mathrm{x}, \mathrm{y}) \geq 100
$$

$$
\begin{aligned}
& \mathrm{x}=0,1,2, \ldots, \mathrm{x}_{\max }-\mathrm{x}_{\min } \\
& \mathrm{y}=0,1,2, \ldots, \mathrm{y}_{\max }-\mathrm{y}_{\text {min }}
\end{aligned}
$$

Finally, the false color image $\mathbf{F}$ with primary components $F_{R}(x, y), F_{G}(x, y)$ and $\mathrm{F}_{\mathrm{B}}(\mathrm{x}, \mathrm{y})$ was made from $_{\mathrm{u}}(\mathrm{x}, \mathrm{y})$, as shown by Figure $9 \mathrm{~b}$ (considering Figure $9 \mathrm{a}$ as the original input image). In this case, the following conditions were applied:

- $F_{R}(x, y)=F_{G}(x, y)=F_{B}(x, y)=255$, if $I_{u}(x, y)=0$.

- $F_{R}(x, y)=F_{G}(x, y)=F_{B}(x, y)=100$, if $I_{u}(x, y)=100$.

- $\mathrm{F}_{\mathrm{R}}(\mathrm{x}, \mathrm{y})=\mathrm{F}_{\mathrm{B}}(\mathrm{x}, \mathrm{y})=0$ and $\mathrm{F}_{\mathrm{G}}(\mathrm{x}, \mathrm{y})=255$, if $\mathrm{I}_{\mathrm{u}}(\mathrm{x}, \mathrm{y})=255$ and belongs to a nucleus.

- $\mathrm{F}_{\mathrm{R}}(\mathrm{x}, \mathrm{y})=\mathrm{F}_{\mathrm{G}}(\mathrm{x}, \mathrm{y})=\mathrm{F}_{\mathrm{B}}(\mathrm{x}, \mathrm{y})=0$, if $\mathrm{I}_{\mathrm{u}}(\mathrm{x}, \mathrm{y})=255$ and belongs to inflammatory cells.

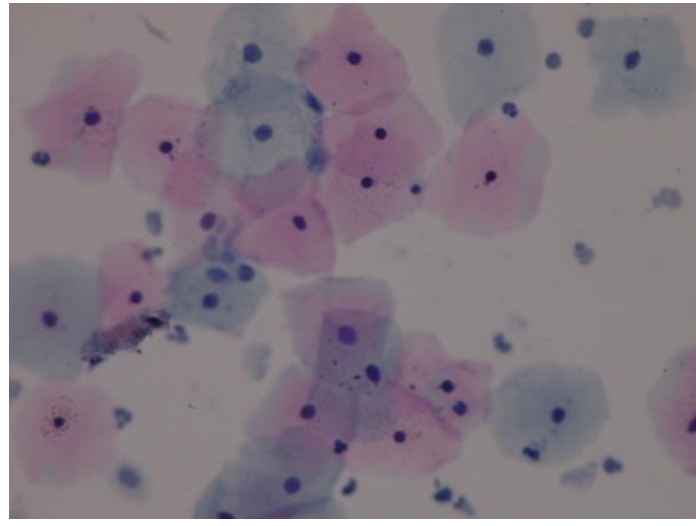

(a) Original Input Image

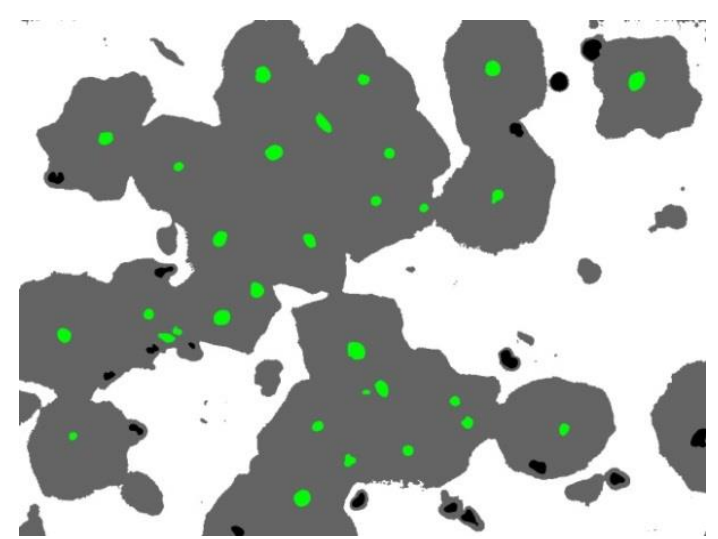

(b) Output False Color Image $I_{F}(x, y)$

Figure 9. False Color Image Formation

\section{Results and Discussion}

In total, 9 different Pap smear samples from 9 different patients from two different medical institutions were collected, with a total of 55 medical images. In those images, 
there were 2317 cells in average, both normal and atypical. The slides were analyzed by four independent pathologists from three different medical institutions, who studied and identified the cell nuclei in the images.

The evaluation of the algorithm performance was carried out by comparing the doctors' evaluation with the results from the software. In this manner, the next quantities were defined:

- $\quad D_{i j}$ : Number of cell nuclei identified by Doctor "i" in Sample "j".

- $S_{\mathrm{ij}}$ : Number of cell nuclei identified by both the software and Doctor "i" in Sample "j".

- $\quad E_{\mathrm{ij}}$ : Nuclei detection efficacy in Sample "j" evaluated by Doctor "i" (Figure $10)$.

$$
E_{i j}=\left(\frac{S_{i j}}{D_{i j}}\right) \times 100 \%
$$

- $\mathrm{E}_{\mathrm{T}}$ : Nuclei detection efficacy for the total of samples and Doctors.

$$
\mathrm{E}_{\mathrm{T}}=\left(\frac{\sum_{\mathrm{i}=1}^{4} \sum_{\mathrm{j}=1}^{9} \mathrm{~S}_{\mathrm{ij}}}{\sum_{\mathrm{i}=1}^{4} \sum_{\mathrm{j}=1}^{9} \mathrm{D}_{\mathrm{ij}}}\right) \times 100 \%
$$

The algorithm successfully recognized $92.3 \%\left(\mathrm{E}_{\mathrm{T}}\right)$ of the total nuclei identified by the doctors in all images. In Figure 10, the percentage of cell nuclei identified $\left(E_{i j}\right)$ versus the Sample for each one of the four Doctors is plotted. The algorithm works in samples from different patients and even from different hospitals, notwithstanding some noise and illumination problems. However, some true nuclei are missing due to faintly staining and little edge contrast. Furthermore, most nuclei tend to not be recognized when too close to each other. In Figure 11, there is a group of suspicious cells nuclei that failed to be segmented as their boundaries are not well defined.

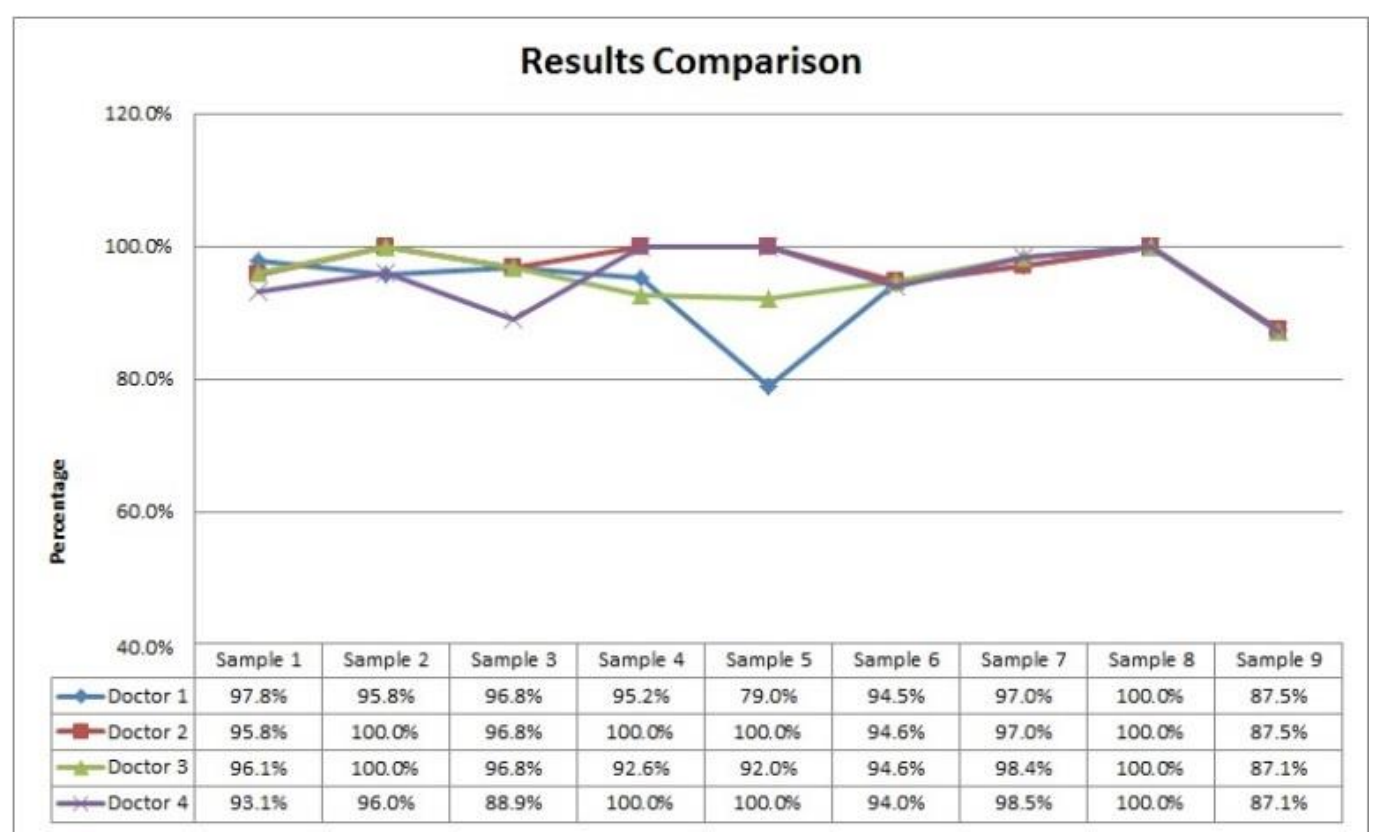

Figure 10. Table of Results 


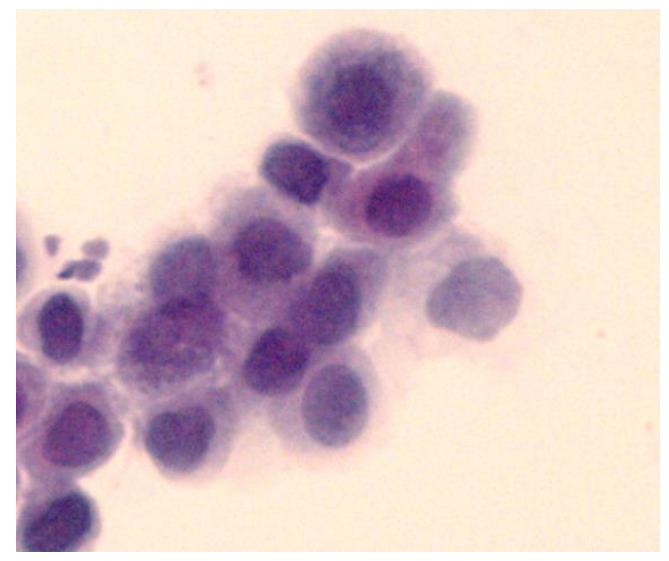

(a) Original Image

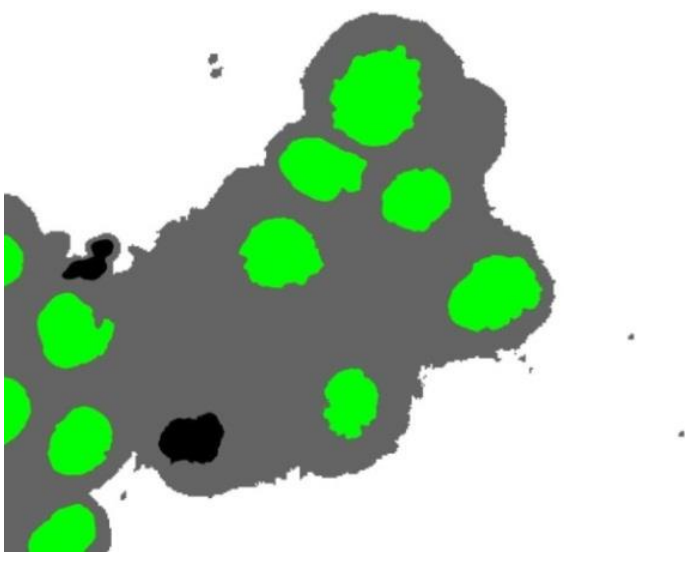

(b) Output False Color Image $I_{F}(x, y)$

Figure 11. Cell Nuclei Misdetection

\section{Conclusion and Future Work}

In summary, the high cervical cancer rate in Peru demands that screening tests for early detection - such as the Pap test - are established as routine procedure. However, this test shows some efficacy problems that require proper technological assistance to improve. In this manner, this paper has worked on an algorithm intended for assisted quality assurance software.

The method has proved to be efficient and computationally inexpensive in detecting cell nuclei. The method overcomes issues related to thresholding algorithms, such as uneven illumination and variations in staining intensity, with a point-to-point analysis. Furthermore, the algorithm successfully detected $92.3 \%$ of the cell nuclei in all the samples, which were not only from different patients but from different hospitals as well. In future work, complementing the detection algorithm with a cell classification part will be required to complete the quality assurance software. Additionally, all the thresholds involved might become adaptive, i.e. the thresholds in the artifact rejection part. An algorithm based on size histograms per sample was developed, but it did not produce the expected results, as it failed when there were very few cells or only atypical ones in the images. Furthermore, it may be possible to add more complex thresholding algorithms, as Otsu's used in [14].

\section{Acknowledgments}

This work would have not been possible without the assistance of the Pathology Service of the Santa Rosa Hospital (Lima, Peru) through the provision of materials, equipment and medical advice. The authors would also like to thank the doctors from the Guillermo Almenara Irigoyen Hospital (Lima, Peru) and the Arias Stella Institute of Pathology and Molecular Biology (Lima, Peru) for their medical advice and interpretations.

\section{References}

[1] Organización Panamericana de la Salud, "Situación de los Programas para la Prevención y el Control del Cáncer Cervicouterino: Evaluación rápida mediante encuesta en 12 países de América Latina”, OPS, Washington D.C. (2010).

[2] W. C. Ramos and D. R. Venegas, "Análisis de la Situación del Cáncer en el Perú, 2013", Ministerio de Salud, Dirección General de Epidemiología, Lima (2013). 
[3] M. R. Salazar, R. Regalado-Rafael, J. M. Navarro, D. M. Montanez, J. E. Abugattas and T. Vidaurre, "El Instituto Nacional de Enfermedades Neoplásicas en el control del cáncer en el Perú", Revista Peruana de Medicina Experimental y Salud Pública, vol. 30, no. 1, (2013), pp. 105-112.

[4] T. Queiro and J. Puñal, "Métodos automatizados de lectura de citología cervical uterina", Axencia de Avaliación de Tecnoloxías Sanitarias de Galicia, Informes de Evaluación de Tecnologías Sanitarias, no. 2013/01, (2013).

[5] S. L. Woodhouse, J. F. Stastny, P. E. Styer, M. Kennedy. A. H. Praestgaard and D. D. Davey, "Interobserver variability in subclassification of squamous intraepithelial lesions", Archives of Pathology \& Laboratory Medicine, vol. 123, no. 11, (1999), pp. 1079-1084.

[6] W. Khalbuss, L. Pantanowitz and A. V. Parwani, "Digital Imaging in Cytopathology", Pathology Research International, vol. 2011, (2011), pp. 1-10.

[7] E. Bengtsson, "Recognizing sign of malignancy - the quest for computer assisted cancer screening and diagnosis systems", Proceedings of IEEE International Conference on Computational Intelligence and Computing Research, (2010) December 28-29, pp. 1-6, Coimbatore, India.

[8] C. Chang, M. Lin, H. Harn, Y. Harn, C. Chen, K. Tsai and C. Hwang, "Automatic Segmentation of Abnormal Cell Nuclei from Microscopic Image Analysis for Cervical Cancer Screening", Proceedings of IEEE 3rd International Conference on Nano/Molecular Medicine and Engineering, (2009) October 18-21, pp. 77-80, Tainan, China.

[9] F. Vacshetto, E. Montseny, P. Sobrevilla and E. Lema., "THREECOND: An automated and Unsupervised Three Colour Fuzzy Based Algorithm for Detecting Nuclei in Cervical Pap Smear Images”, Proceedings of Ninth International Conference on Intelligent Systems Design and Applications, (2009) November 30December 2, Pisa, Italy.

[10] I. Muhimmahi, R. Kurniawan and I. Indrayanti, "Automated Cervical Cell nuclei Segmentation Using Morphological Operation and Watershed Transformation", Proceedings of IEEE International Conference on Computational Intelligence and Cybernetics (CyberneticsCom), (2012) July 12-14, pp. 163-167, Bali, Indonesia.

[11] M. Plissiti; C. Nikou and A. Charchanti, "Watershed-based segmentation of cell nuclei boundaries in Pap smear images", Proceedings of 10th IEEE International Conference on Information Technology and Applications in Biomedicine (ITAB), (2010) November 3-5, pp. 1-4, Corfu, Greece.

[12] M. Plissiti and C. Nikou, "Overlapping cell nuclei segmentation using a spatially adaptive active physical model", IEEE Transactions on Image Processing, vol. 21, Issue 11, (2012), pp. 4568-4580.

[13] R. Moshavegh, B.E. Bejnordi, A. Mehnert, K. Sujathan, P. Malm and E. Bengtsson, "Automated segmentation of free-lying cell nuclei in Pap smears for malignancy-associated change analysis", Proceedings of 34th Annual International Conference of the IEEE Engineering in Medicine and Biology Society (EMBC), (2012) August 28-September 1, pp. 5372-5375, San Diego, California.

[14] R. Malviya, S. P. K. Karri, J. Chatterjee, M. Manjunatha and A. K. Ray, "Computer assisted cervical cytological nucleus localization", Proceedings of TENCON 2012 - 2012 IEEE Region 10 Conference, November 19-22, pp. 1-5, (2012), Cebu, Philippines.

[15] M. Frucci and G. Sanniti di Baja, "Oversegmantation reduction in watershed-based grey-level image segmentation", International Journal of Signal and Image Systems Engineering, vol. 1, no. 1, (2008), pp. 4-10.

[16] P.S.J. Sree, P. Kumar, R. Siddavatam and R. Verma, "Salt-and-pepper noise removal by adaptive medianbased lifting filter using second-generation wavelets", Signal, Image and Video Processing, vol. 7, Issue 11, (2013), pp. 111-118.

[17] R. Gonzalez and R. Woods, "Digital Image Processing,” 3rd. Ed., Prentice Hall, New Jersey, (2008).

\section{Authors}

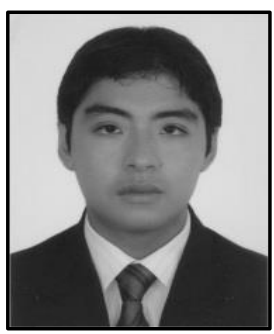

Julio Oscanoa, he received the B.S. degree in Electrical Engineering from the Peruvian University of Applied Sciences (UPC), Lima, Peru, in 2013.

Since 2014, he has been working as a researcher at the Jicamarca Radio Observatory, Lima, Peru. His research interests include image and signal processing, and medical imaging. 


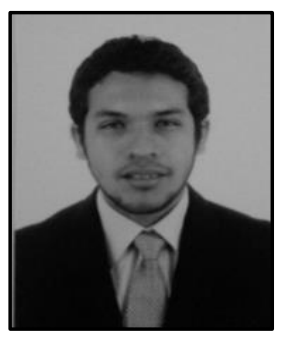

Marcelo Mena, he received the B.S. degree in Telecommunications Engineering from the Peruvian University of Applied Sciences (UPC), Lima, Peru, in 2013. His research interests include encoding and decoding of signals and protocols.

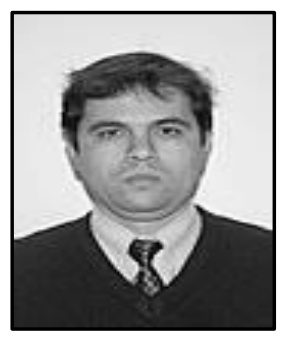

Guillermo Kemper, he received the B.S. degree in Electrical Engineering in 1994 from the Antenor Orrego Private University (UPAO), Trujillo, Peru. In years 1996 and 2001, he obtained a Master degree in Electrical Engineering and a $\mathrm{PhD}$ in Electrical and Communications Engineering, respectively, from the State University of Campinas (UNICAMP), Brazil.

He has taken part for more than 3 years in the CPqD research agreement between the Brazilian Telecommunications Company Telebrás and UNICAMP, developing and designing audio and video coders. Currently, he is working as a research professor for the undergraduate and postgraduate programs of the schools of Electrical Engineering from the San Martin de Porres University (USMP), Lima, Peru, and the Peruvian University of Applied Sciences (UPC), Lima, Peru. In addition, he is a researcher at the National Institute for Research and Training in Telecommunications (INICTEL-UNI), Lima, Peru. His research interests include voice, audio, images and video processing, digital communications and digital television. 
International Journal of Multimedia and Ubiquitous Engineering Vol. 10, No. 2 (2015) 